\title{
HISTORY OF STEREOLOGY
}

\author{
ANETA GĄDEK-MOSZCZAK \\ Cracow University of Technology, Department of Mechanical Engineering, Institute of Applied Informatics, 37 \\ Jana Pawła II Av., 31-864 Kraków, Poland \\ e-mail: gadek@mech.pk.edu.pl
}

Over 50 years ago, in 1961, the International Society for Stereology has been established. Half a century is an impressive time, and an excellent proof that the founders of the Society have made an important and necessary initiative.

Since its founding, the Society has aimed to bring together scientists working in different fields of science and applying and developing stereological methods in their research work. The participants of the first, founding meeting of the International Society for Stereology, which took place in May, 1961 in Black Forest (Feldberger Hof) in Germany, were: G. Bach, H. Elias, M. Gihr, H. Haselmann, H. Haug, A. Henning, A. Hossman, C. Kraus, R. Lorenz and W. Treff (Haug, 1987). First president of the ISS was $\mathrm{H}$. Elias, the originator of this project. Founders of the Society represented four fields of science: anatomy, biology, mathematics and medicine as well as three countries: USA, Federal Republic of Germany and Norway. The idea to create a new interdisciplinary scientific society proved to be extremely successful. It was a perfect answer to the needs of knowledge exchange, as well as unprecedented chance for personal contact of two groups of scientists: those who formed the mathematical foundations for new solutions and those trying to apply them in various scientific disciplines. Great response of the scientific community on a new society was reflected in rapid increase in the number of members of the Society from the initial 10 to over 150 in 1962 at the first Congress in Vienna, Austria. 81 members from Europe, 70 from America, 6 from other continents, representing not only biological sciences (82), but also materials science, mathematics and 22 other disciplines, confirmed the demand on stereological methods and their increasing importance.

Nowadays it is difficult to list all disciplines where stereology is applied, starting from biology and medicine, through materials science, geology and agriculture, up to military systems, biometry, meteorology, geography, physics, astronomy, sophisticated vision systems and even history or art sciences. The strength of the stereology as a scientific discipline lies in its multidisciplinary character and even now, in the century of the digital revolution, doesn't become obsolete (Chermant, 1992). Over the last five decades stereology has responded to the challenges of the times. Its creators and enthusiasts have adapted this field of science to the current challenges existing practically everywhere if only an image (formally: section or projection) is a source of information.

Initial manual methods for assessment of stereological parameters have been gradually replaced by image analysis algorithms that constitute an excellent tool to increase the accuracy, efficiency and objectivity of stereological analysis. With the widespread use of image analysis systems, which initially were highly specialized research units, stereology and image analysis became mutually enriched and complementary. Can we talk about stereology today, aside from the aspects of computer methods that are used for their applications? This question is not new, and nowadays the answer seems to be pretty obvious, but it is worth to recall the one of the interesting considerations of Jean Louis Chermant, past President of ISS, which he presented in an address to the participants of Stermat IV conference prepared by the Polish Society for Stereology in 1994. This address has been illustrated by humorous drawings by Leszek Wojnar. We publish here three of them that reflect some severe discussions of these days and constitute a short story. In the first one a seriously looking guy insists on a young man that he should ADD image analysis to stereological analysis. In contrast, in the second cartoon, an old-looking (possibly) professor explains that stereological methods should be strictly separated from image analysis. In the third cartoon the young scientist answers to the older one that he will combine these methods: "I will do stereology AND image analysis". The present journal has been renamed in 1999 from Acta Stereologica to Image Analysis and Stereology. Please, note that currently the name of our society is: International Society for Stereology and Image Analysis! 

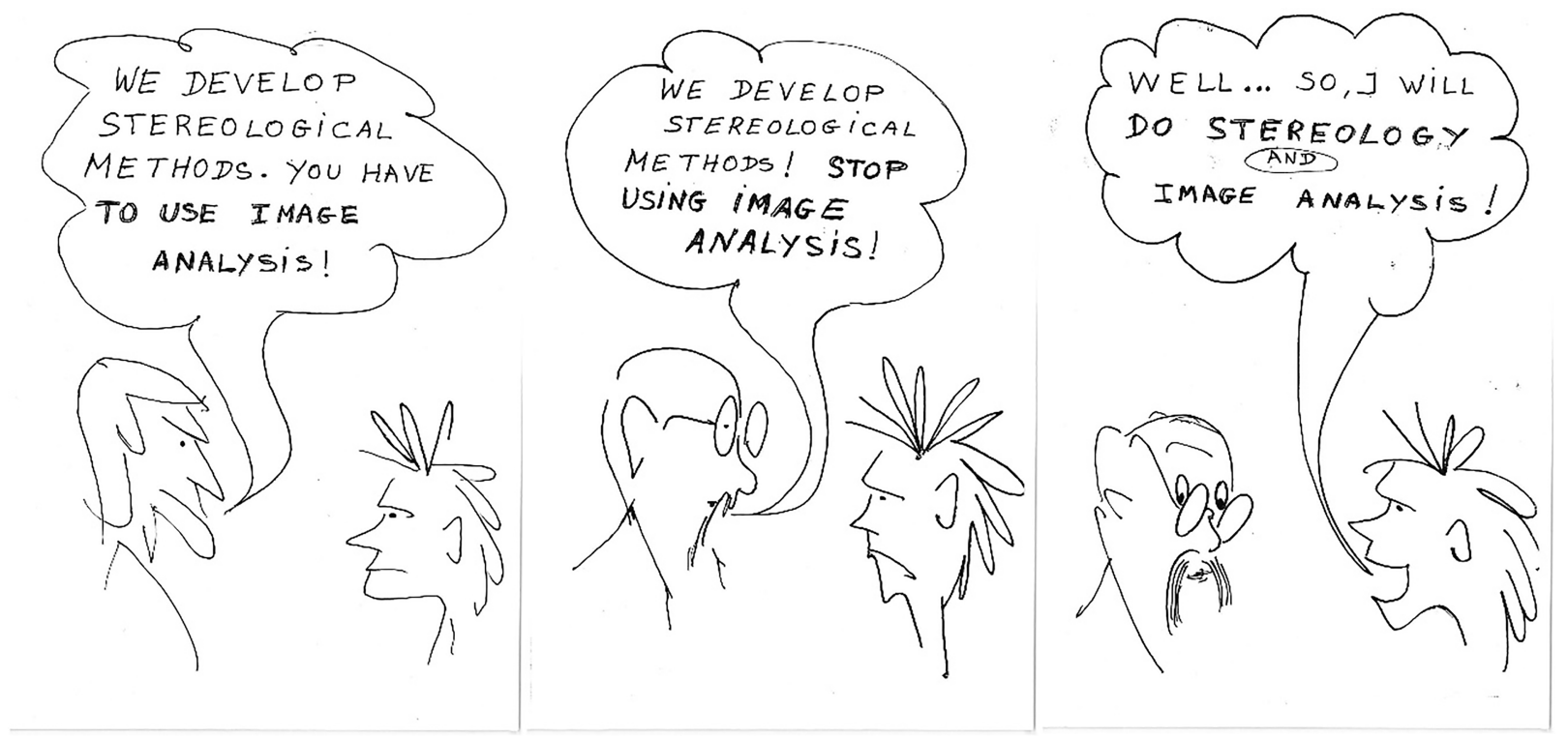

Drawings by Leszek Wojnar

In his address Jean-Louis Chermant has written: "Of course, Image Analysis, Mathematical Morphology, Stereology are all fantastic tools. But perhaps some of you are of the opinion that one of these tools is far more fantastic than the others? If such is the case, I suggest that here again some borders should be abolished".

So, in fact he has been a prophet as regard the future of our Society.

Another aspect of modern stereology applications, that makes the original definition of stereology ought to undergo reformulation and extension, is possibility of analysis of 3 dimensional images and 3D mode-lling of the structures and their properties.

As it was mentioned, the idea of founding the International Society for Stereology was to create a framework for cooperation that would allow the exchange of experiences and achievements, as well as to allow systematization and unification of developed methods. Thanks to a series of International Congresses for Stereology (now Stereology and Image Analysis) and European Congresses for Stereology, the idea of stereology and its development is continuously promoted since 1962.

Behind every organization, also scientific one, stand people who create its shape and character, and the organization is as great as the people who make it. We would like to invite you to familiarize yourself with the series of articles prepared in the cycle: History of Stereology. The cycle will continue in the next issue of IAS. These papers give an emotional, far from scientific stiffness, presentation of the history of stereology observed with the eyes of today's active members of the Society, representing different countries and cultivating different branches of science. It is an excellent occasion for some of us to remind and to others, young generation of the stereologists in particular, to get acquainted with extraordinary scientists and their interesting, often breakthrough achievements, all those who create this new discipline of science. Without their determination and devotion to the idea of development and promotion stereology, it would be probably not so widely applied.

This is a great opportunity to take a small journey back in time to recall the origins of stereology, and even to the time where stereology wasn't known as a defined field of science. It is also worth deeper insight to different paths of its development that have taken place in various countries from which its representatives came. I would like to warmly invite all the readers to this journey through the time, and I hope that you will find it interesting and inspiring. Please, keep in mind that you have to wait fifty years for the next chance to make such a review!

\section{REFERENCES}

Chermant, JL (1992). Image analysis and related techniques: who is not interested? Acta Stereol 11 (Suppl. I): 15-37.

Haug, H (1987). The first ten years after the foundation of the International Society for Stereology in 1961. Acta Stereol 6 (Suppl II):35-42. 